Nihal Nagi Abdel Latif Abu el Naga

\title{
A Corpus-based Investigation of Conceptual and Pictorial Metaphor of Depression in MD and BPD Patients' Discourse
}

\section{Abstract}

Nihal Nagi Abdel Latif Abu el Naga

This paper examines the representation of major depression (MD) and bipolar disorder (BPD) from a cognitive linguistic perspective. Investigating psychological disorders linguistically has been under the water for almost a decade now, with the pioneering study of Eynon (2002). Many recent linguistic studies have approached mental health discourse, in an attempt to better understand and deal with various physiological and psychological problems. Major depressive disorder (MD) "is a common illness worldwide, with more than 300 million people affected...is the leading cause of disability worldwide, and at its worst, [it] can lead to suicide." ("WHO"). On the other hand, Bipolar disorder is one of the fast spreading psychological disorders. In fact, according to the World Health Organization, bipolar disorder is the sixth leading cause of disability in the world. Working with depression patients and helping them explore and identify their disorder is the first step towards treatment. The present paper is a depression-corpus-based analysis of the verbal and visual discourse of patients to investigate how depression is framed linguistically, drawing on Lakoff and Johnson's seminal Conceptual Metaphor Theory (1980) and Forceville (2008) Pictorial Metaphor Theory. The verbal data show four main patterns of conceptual metaphors: DEPRESSION IS DISEASE, DEPRESSION IS COMPANION, DEPRESSION IS ABYSS, and DEPRESSION IS ENEMY. Visually, DEPRESSION is framed as ENEMY, DEATH and ABYSS. Psychiatrists and psychologists may find the findings of this work helpful as they continue to study mental health discourse.

Keywords: major depression, bipolar depression disorder, conceptual metaphor theory, pictorial metaphor theory, cognitive linguistics.

\section{Introduction:}

Digital space has offered the opportunity for many people with mental illness to make sense of their experiences, of themselves, and of the social climate in which they find themselves immersed (Ginsberg 2012). This paper examines the representation of major depression (MD) and bipolar disorder (BPD) from a cognitive linguistic perspective. Investigating psychological disorders linguistically has been under the water for almost a decade now, with the pioneering study of Eynon (2002). Many recent linguistic studies have approached mental health discourse, in an attempt to better understand and deal with various physiological and psychological problems. The present paper is a corpusbased study of the visual and verbal representation of depression to investigate how it is framed linguistically, drawing on Lakoff and 
Johnson's seminal Conceptual Metaphor Theory (1980) and Forceville (1994, 2008) model of analyzing non-verbal metaphors.

Conceptual Metaphor Theory (CMT) sets off from the premises that metaphor is frequently used to understand inherently unstructured abstract concepts in more accessible concrete terms. We use metaphors not only to speak about certain aspects of the world but to "think about" them. Linguistic framing shapes the way we perceive the world by constraining how we gather information about people, events and situations (Lakoff \& Johnson, 1999). Developments in CMT ((Paprotte and Dirven 1985; Lakoff and Johnson 1999; Kövecses 2003, 2015; Grady 1997, 2007; Charteris-Black, 2012) have resulted in establishing universal conceptual metaphors such as LOVE IS JOURNEY, ANGER IS HOT FLUID and HAPPINESS IS UP.

The main contribution of CMT lies in its ability to help metaphor analysts in particular, and linguists in general to relate human's bodily and worldly experience to language on the one hand and their linguistic repertoire on the other. Moreover, CMT is a tool for examining the process of human cognition via the mirror of language, being the main vehicle of expression available to humans. In this light, instances of conceptual metaphors have been investigated and a body of CM literature is created.

Forceville (2008) has taken research on conceptual metaphor into a new horizon with his Pictorial Metaphor Theory (PMT). Being a model of thought rather than a linguistic feature, metaphor as a pattern of thought is perceived by cognitive linguists as can be expressed on nonverbal ways, such as pictures and gestures (cited in Geeraerts and Cuyckens, 2007, p.189). Drawing on the cognitive basis of metaphor use, Forceville developed a pictorial/multimodal model of metaphor analysis.

One of the main areas where CMT has been particularly helpful is the psychological one. People, with one or another of mental or psychological disorders, are partly examined via one-to-one interviews with psychologists or psychiatrists to enable them to assess the degree and nature of the disorder. This is, of course, besides other more specialized examinations, where both procedures target treatment.

The present work falls within the interdisciplinary realm of cognitive linguistics and psychology. It investigates the verbal and visual expression of those people with Major Depression (MD) or Bipolar Depression (BPD). MD "is a common illness worldwide, with more than 300 million people affected... is the leading cause of disability worldwide, and at its worst, [it] can lead to suicide." ("WHO, 2018"). On the other hand, BPD is one of the fast spreading psychological disorders. In fact, 


\section{Nihal Nagi Abdel Latif Abu el Naga}

according to the World Health Organization, bipolar disorder is the sixth leading cause of disability in the world. Working with depression patients and helping them explore and identify their disorder is the first step towards treatment. According to National Institute of Mental Health (NIMH), "Proper diagnosis and treatment help people with bipolar disorder lead healthy and productive lives. Talking with a doctor or other licensed mental health professional is the first step for anyone who thinks he or she may have bipolar disorder" ("NIMH"). Hence, examining their discourse is seen as a prerequisite for proper diagnosis.

Hence, the present study analyses the discourse, highlights instances of conceptual metaphors that pervade in the discourse, and categorizes these metaphors along the lines elaborated by Lakoff and Johnson.

On another level, it is not uncommon to find that "individuals with mental illness may not always be verbally expressive; however, they may display emotions through creative expressions such as music, poetry or art" ("psychiatrictimes"). Accordingly, art therapy is a well-established profession to explore the feelings and reduce anxiety of patients of depression. In this light, the present paper equally explores how metaphors of depression are expressed in visual mode in the drawings by either MD or BPD patients, in the light of PMT.

Both threads of analysis aim at better exploring how people with depression conceptualize and represent their disorder. Whereas much work has been done on conceptual metaphors in public discourse, political speeches and economic discourse, the research which relates conceptual metaphor and psychological disorders is still quite limited and understudied.

\section{Objective and research questions:}

The present study investigates the drawings and discourse of people with either Major or Bipolar depression. It examines how they frame their psychological disorder visually and verbally. The study aims to answer the following questions:

1. What are the different DEPRESSION metaphors that feature across the data?

2. What are the most dominant metaphors across the MD and the BPD corpus?

3. What are the main similarities and differences between the two selected corpora?

4. How do images metaphorically represent depression?

5. What are the similarities and differences between the verbal and non-verbal representation?

6. How could the linguistic framing of depression be interpreted? 


\section{Theoretical Framework:}

\section{Conceptual Metaphor Theory}

The main breakthrough of Lakoff and Johnson's work resides in how they redirected the conceptualization of metaphors use in language. Whereas almost all literature on metaphors lent it an ornamental function in discourse, particularly in literary discourse, in Metaphors We Live By (1980), metaphor was established as a feature of everyday talk. In fact, it was seen as an innate cognitive faculty which helps people process abstract concepts and ideas. So ANGER is seen as a FLUID IN A CONTAINER, LOVE AS A JOURNEY, and ARGUMENTS AS WAR. Lakoff (2012) states that

The metaphor involves understanding one domain of experience, love, in terms of a very different domain of experience, journeys. More technically, the metaphor can be understood as a mapping ... from a source domain (in this case, journeys) to a target domain (in this case, love) (p.225).

The key term domain is borrowed from Langacker's definition of domains as "necessarily cognitive entities: mental experiences, representational spaces, concepts, or conceptual complexes' (Langacker, 1987, p. 147). In other words, domains are conceptual entities of varying levels of complexity and organization (Evans and Green, 2006, p.). Source domains "correspond to concrete, simple, familiar, physical and welldelineated experiences such as motion [and] bodily phenomena" (Semino, 2008, p. 6). Target domains, in contrast, are "diffuse", abstract, and "lack clear delineation", as Kövecses (2010a ,p. 23) explains.

Metaphors, in this theoretical model, spring from our physical existence and bodily experience. In fact, one of the sub-categories of metaphor- orientational metaphors- reside in how we make sense of our bodies and hence other related objects. Lakoff and Johnson (1980) classify metaphors into three main types:

1. Structural metaphors: In this type, the "target domain is the source domain"- type of metaphors, where one entity (the abstract concept/ emotion) is mapped onto another (the concrete/ accessible). This involves systematic correspondences between two related ideas. Accordingly, when LOVE is seen as a JOURNEY, this 
entails conventional cross-domain correspondences where the relationship is seen as a ROAD, the lovers as PASSENGERS, the hardships in their relation as HURDLES, etc.

2. Ontological metaphors: are instances where "events, activities, emotions, ideas, etc. [are seen] as entities and substances" (Lakoff and Johnson, 1980, p.25). So ANGER is seen as a FLUID, HEART as a CONTAINER, and INFLATION is an ENTITY.

3. Orientational metaphors: this type of metaphor is one of the pivots of the theory

where metaphors are seen in relation to bodily experience; they are "experientially-motivated". As noted by Lakoff and Johnson, orientational metaphors have "basis in our physical and cultural experience.... These spatial orientations arise from the fact that we have bodies of the sort we have and they function as they do in our physical environment" (p. 14). This explains why we have high spirits, and avoid falling in the abyss of depression.

As noted by Grady (2007), mapping is a key term within the theory, where it refers to "systematic metaphorical correspondences between closely related ideas" (p.190). Hence, conceptualizing LIFE as a JOURNEY would result in seeing people as passengers, difficulties as road hurdles, and objectives as a destination. This is seen as a type of systematic projection of source domain elements on target domain ones. On the other end of the continuum, the asymmetric directionality is another key notion. Accordingly, whereas it is "meaningful to refer to the foundations of a theory but meaningless to refer to the postulates of a building" (Grady, 2007, p. 191).

Another key concept, which features in the selected corpus, is what Lakoff (1993) calls the event structure metaphor. "This is actually a series of metaphors that interact in the interpretation of utterances" (Evans and Green,2006, p. 299). Examples of these are: STATES ARE LOCATIONS, CHANGE IS MOTION, CAUSES ARE FORCES, PURPOSES ARE DESTINATIONS, DIFFICULTIES ARE IMPEDIMENTS TO MOTION and LONG-TERM PURPOSEFUL ACTIVITIES ARE JOURNEYS. These event structure metaphors are slightly instantiated in the examined data where DEPRESSION IS A JOURNEY, TREATMENT IS THE DESTINATION, and RELAPSES ARE IMPEDIMENTS TO MOTION.

Since their seminal work came into light, as a major approach within cognitive linguistics, a plethora of studies has been done either to 
validate or build on the theory. Two contributions to the theory are of special place: Kovasces (2005) work on metaphors and Forceville's (2008) on pictorial conceptual metaphor.

\section{Pictorial Metaphor}

If metaphor characterizes thinking, and is thus not an exclusive attribute of language, it should be capable of assuming non-verbal and multi-modal manifestations, as well as the purely verbal ones that have been of central concern of metaphor studies. If metaphor does not necessarily appear in verbal guise, cognitivist scholars can hardly afford to ignore the pictorial realm.

Drawing on these premises, Forceville (1994) developed the theory of Pictorial Metaphor, introducing four major types of pictorial metaphor. This model was later revised (Forceville, 2002), where new terms were given to the pictorial metaphors and a new type (verbo-pictorial metaphor) was introduced. In the present study, Forceville (2002) pictorial/multimodal metaphor model is adopted.

According to Forceville $(1994,2008)$, a pictorial metaphor is a static representation that can take different forms. It is considered as visual representation of metaphorical thoughts and concepts. As with the case of verbal metaphor, a pictorial metaphor involves understanding an element within the picture (metaphorical target) in terms of another (metaphorical source) so that "a visually represented object can be used as the source domain of a pictorial metaphor" (Forceville, 2002). Forceville defines a visual metaphor in terms of the replacement of an expected visual element by an unexpected one. In order to speak of a metaphor, he argues, there must be no 'pre-existent or conventional connection' (Forceville, 1994, p. 2).

Forceville differentiates between four main types of pictorial metaphors:

1. Hybrid type of pictorial metaphor: where the metaphor results from the combination of two diverse elements that belong to different domains, into one unified concept. The interpretation of this hybrid depends on understanding one of the two parts in terms of the other. An example is COMPUTER COMPONENTS ARE NOTES IN A MUSICAL COMPOSITION.

2. Contextual type of pictorial metaphor: where the metaphor results from the occurrence of an element in the picture (target domain) in a context that is traditionally occupied by another element (source domain). An example is LUCKY STRIKE IS BAR OF SOAP.

3. Pictorial Simile: A phenomenon that is experienced as a unified object is juxtaposed with a unified object belonging to a different category in such a manner that the first is understood in terms of 
the second. An example is DOMMELSCH BEER IS (LIKE) LEANING TOWER OF PISA.

4. Integrated metaphor: A phenomenon that is experienced as a unified object or gestalt is represented in its entirety in such a manner that it resembles another object or gestalt even without contextual cues. An example is SENSEO COFFEE MACHINE IS SERVANT.

As mentioned by Forceville, the major difference between contextual type of metaphor and simile metaphor is that whereas the former is understood because the metaphorical target is identified in a visual context that "necessarily evokes" the metaphorical source. On the other hand, simile metaphor "depicts the source" itself.

\section{Review of Literature}

The literature on CMT has been heaping up along the past two decades. This has led to the establishment of what is termed by Grady (1997) as primary metaphors versus compound metaphors. Primary metaphors are foundational metaphors, and relate concepts that are 'equally' basic such as IMPORTANCE IS SIZE, SIMILARITY IS CLOSENESS, and QUANTITY IS ELEVATION, as well as many others. Primary metaphors are "a set of pervasive conceptual metaphors which seem to reveal with special directness the deep relationships between word usage, conceptual structure, and the way we experience the world" (Grady, 2007, p. 192). A compound metaphor such as LIFE IS A JOURNEY is one that rests on a number of primary metaphors.

An extensively studied area within the framework of conceptual metaphor is emotion metaphors, being one of the best researched domains (Kövecses, 2000b). Basic emotions introduced in Kövecses (2000b) were anger, happiness, sadness, fear and love. This model of analyzing emotion metaphors was later adopted by a number of scholars. Matsuki (1995) observed that all the metaphors for anger in English can also be found in Japanese. Ning Yu (1995) observes this specific metaphor does not exist in Chinese. He also points out that Chinese shares with English all the basic metaphorical source domains for happiness, UP, LIGHT, FLUID IN A CONTAINER, but an alternative metaphor that Chinese has does not exist in English, is HAPPINESS IS FLOWER IN THE HEART. Shahrazad et al. (2012) also conclude that:

although there were some cultural differences in conceptualizing these five basic emotions- namely anger, happiness, sadness, fear, and love in English and Persian due to the emphasis laid on some aspects of metaphor and entailments (partially the same pattern), 
the two languages share most of the general conceptual metaphors in describing these five emotions (p. 206).

One of the recent developments in the theory, which is relevant to the present research is the one conducted by Lakoff (2008) on the study of metaphors in the brain. This led to the emergence of a "neural theory of metaphor". According to this theory, individual neurons in the brain form neuronal groups, called "nodes". There can be different types of neural circuits between the nodes. In the "mapping circuit" that characterizes metaphor, there are two groups of nodes corresponding to source and target domain. The circuitry between the two groups of nodes will correspond to the mappings, or correspondences. In primary metaphors, one group of nodes represents a sensorimotor experience in the brain, while the other represents an abstract, subjective experience (Kövecses, 2017, p. 32)

Working on conceptualizing emotions has attracted the research engine of a multitude of researchers, starting with Lakoff and Johnson themselves. In this respect, the work of Kövecses (2003) on the model of linguistic expression of metaphor, would be considered the most comprehensive. Lakoff and Johnson (1980) propose that the conceptual structure of emotions emerges through metaphorization of more concrete, palpable concepts such as heat, cold, fire, liquid or spatial orientations. Along these lines, the ontology of the concepts of emotions can be explained through mappings between target domains (e.g., emotions) and concrete source domains, such as spatial or temperature concepts, as in HAPPY IS UP or ANGER IS HEAT. This view is supported by numerous analyses of metaphorical expressions used with reference to emotions such as anger, hope, love and lust, among others (Kövecses, 2000; Lakoff, 1987).

One of the latest trends in conceptual metaphor is the one which examines "the connection between metaphorical aspects of our cognitive activities and the varied set of contextual factors that influence the emergence of metaphors". These are more context-bound or, as Kövecses (2010b) calls them, are "context-induced". Kövecses concludes that metaphors can be categorized as either primary, cultural-bound or context-induced. In other words, "we seem to have a cline of metaphors, ranging from universal primary metaphors to non-universal contextinduced ones. In other words, metaphors can derive from the body, cultural specificities, and also the more general context".

Metaphor Identification Procedure (MIP) is another attempt of identifying metaphors via corpus tools. A project carried out by a group of scholars called Pragglejaz started the Pragglejaz procedure in 2007, 


\section{Nihal Nagi Abdel Latif Abu el Naga}

where the "procedure aims to determine the relationship of a particular lexical unit in the discourse and recognize its use in a particular context as possibly metaphorical" (Pragglejaz, 2007, p.2).

As previously mentioned, the interdisciplinary research merging cognitive linguistics with psychiatric and medical investigations came into the foreground with the work of Eynon (2002). For example, Lott et al. (2002) examine the speech output of schizophrenic, bipolar and depressive patients. They conclude that "linguistically deviant speech characteristics represent an independent syndrome complex manifested at varying intensities across mental illnesses" (p.225). The impact of metaphor use to describe cancer and AIDS has been explored in the field of health discourse (Frank, 1995; Sontag, 1989). Based on the principles of the Conceptual Metaphor Theory developed by Lakoff and colleagues, recent works have studied metaphors of depression in the case of English. Charteris-Black (2012) carries out a gender-based dichotomy of metaphors of depression, where depression is mostly seen as a container, in contrast to 'self' seen as a container. Also, Demjén (2011) calls for the application of linguistic methods in "deeper understanding of the lived experiences of psychological disorders, with special reference to The Unabridged Journals of Sylvia Plath, as a case study of the experience of depression. On another side, McMullen \& Conway (2002) suggest "increased effectiveness of depression medications framed metaphorically as solving those bodily problems". In their work on the linguistic framing of mental illness, Reali, F. et al (2015) discuss the role of conceptualization of psychological problems, with special focus on depression in Latin American students' discourse. They conclude that depression is metaphorically seen as a tree/plant or as an opponent.

Working on visual metaphors has been studied by various researchers since the pioneering work of Forceville (1994). A particularly relevant study is the one conducted by Forceville and Paling (2018) examining the metaphorical representation of DEPRESSION in short, wordless films. In their study, Forceville and Paling stress the importance of the "affordances and constraints" of the medium (animation film, in this case) in interpreting the conceptual metaphor in a way different from verbal or static visuals. Another illuminating study is the one conducted by El Refaei (2014) on two graphic memoirs to show how comics artists may transform metaphors of depression by drawing on socio-cultural conventions.

Adopting the view that a pictorial metaphor is essentially a pictorial expression of a metaphorical way of thinking, El Refaei (2003) examines four Australian cartoons to show how visual metaphors are primarily visual representations of metaphorical thoughts or concepts. 
A Corpus-based Investigation of Conceptual and Pictorial Metaphor of Depression in MD and BPD Patients' Discourse

Similar studies focusing on the role of pictorial metaphors in advertising include De la Rosa (2009) study on pictorial metaphors in Spanish advertisements. Similarly, Alousque (2015) similarly examines the role of text in the identification of visual metaphors.

Another thread of research tries to link visual metaphor to earlier models. In their paper, Feng and O'Halloran (2013) try to link visual metaphor to social semiotic framework to prove how the latter is able to provide a comprehensive account of the visual realization of metaphor. In addition, the study also offers a cognitive explanation of how resources like camera positioning and composition acquire meanings.

\section{Sources of Data:}

The data under investigation consists of two types of corpora: verbal and visual. A verbal corpus featuring a compiled 1.8 million-word corpus of web-collected posts and blogs written by people who suffer from BPD or MD from mental health forums. The corpus is divided into two main subcategories: the major depressive (MD) corpus amounting to 900,000, and the Bipolar depression (BPD) corpus (900,000 words). The second corpus is a collection of images and paintings drawn by depression patients during different episodes of depression and uploaded to the website Borepanda retrievable through:https://www.boredpanda.com/depression-throughart/?utm_source $=$ search.yahoo\&utm_medium $=$ referral\&utm_campaign $=0$ rganic. This forum includes more than 100 (137 drawings) of depression phases.

\section{Methodology}

This study adopts a quantitative approach to analyzing the verbal data, represented in the MD and BPD verbal corpus. The verbal corpus is uploaded to the Sketch Engine software, where it is automatically compiled. Two separate files are compiled, one including the MD discourse and another the BPD discourse. The selected depression corpus is uploaded to the Sketch Engine corpus analysis tool. Sketch Engine is "a corpus manager and text analysis software developed... to enable people studying language behaviour ... to search large text collections according to complex and linguistically motivated queries" ("Wikipedia"). In the present paper, the author makes use of three of major features of the corpus tool: namely, word sketches, concordances and collocations to identify the instances of occurrence of the selected target domain depression.

Conceptual metaphors are identified by extracting all the sentences which include the target domain word depression. Using the Sketchengine concordance and collocate tool, the researcher identifies 


\section{Nihal Nagi Abdel Latif Abu el Naga}

lexical items which include the target word in a frame of interest. For example, the words symptoms, cure, heal, medication, curable, etc. instantiate an implicit mapping between depression and disease, hence the DEPRESSION IS DISEASE metaphor is identified. It is worth noting here that dealing with depression as a physiological, rather than a psychological disorder, is the basis of this conceptual metaphor. The DEPRESSION IS AN ABYSS metaphor includes collocates such as fall in/into, plunge in, slip in, get out of, etc. The DEPRESSION IS ENEMY metaphor is extracted from instances where depression collocates with battle, combat, fight, and beat. Expressions tagged as instances of the metaphor of DEPRESSION IS A COMPANION are extracted through the prepositional phrase living/live with depression. This procedure is followed in both sub-corpora.

A qualitative approach is adopted in analyzing the visual data, where the drawings are analysed along the lines of Forceville (2002) model. This aims at highlighting the type of pictorial metaphors that exist within the corpus, highlighting the most and the least prevalent. It is worth noting that other frameworks of analyzing data could have been used in the process of analysis, such as Kress and van Leeuwen's (2006) model of reading images. However, Forceville's model is chosen as it is consistent with the cognitive approach adopted in the study.

Finally, a comparison is drawn between the verbal and visual data, to point out the major similarities and differences between these two modes of expression in the representation of depression.

\section{Analysis:}

Analysis of verbal corpus:

The current analysis is designed to provide an account of the major conceptual metaphors of depression used in the discourse of MD and BPD patients. Conceptual metaphor is used to unveil how people with mental health/psychological problems, think about their disorders. To achieve this goal, the selected corpus is quantitatively examined, first to identify the different DEPRESSION metaphors that occur in the discourse, second, to investigate the frequency of these different conceptual metaphors. The results are further qualitatively interpreted in the Results and Discussion section.

\section{Corpus}

The total hits for the word depression is 3,356 in the MD corpus. The researcher could identify 268 metaphors of depression as follows: 95 expressions are tagged as some version of the metaphor DEPRESSION IS ENEMY, 90 expressions are tagged as some version of the metaphor DEPRESSION IS DISEASE, DEPRESSION IS AN ABYSS metaphor records 65 times. The final conceptual metaphor tagged is DEPRESSION 
IS COMPANION hitting 43 times. Other sentences include rather neutral expressions such as manage, get, deal with, or have depression, which are not included within the statistics.

In this respect, it is worth noting that both DEPRESSION IS DISEASE and DEPRESSION IS ABYSS are examples of structural metaphors. They even feature as event structure metaphors, which are defined by Evans and Green (2006) as "a series of metaphors that interact in the interpretation of utterances" (p. 299). That is why it is found that the persons who speak of their depression as a disease see recovery as an attainable goal, and stress the role of medication to help cure them from depression. This is a typical example of what Lakoff and Johnson's idea of mapping, where systematic metaphorical correspondences occur between the source and the target domains. On the other hand, DEPRESSION IS ENEMY and DEPRESSION IS COMPANION metaphors are to be categorized as ontological metaphor, as depression is seen as an entity. It is noteworthy that the enemy here is identified with an animal in a couple of instances, with sentences such as "Once again, I thought I could beat my beast alone". However, this has extremely low frequency within the corpus.

The following examples illustrate the main patterns observed in the MD corpus data:

\subsection{DEPRESSION IS DISEASE:}

1. doc\#3...those two steps were the most crucial in treating and healing my severe

depression....

2. doc\#3...there had to be some other way to cure my depression and to find peace of mind...

\subsection{DEPRESSION IS COMPANION:}

3 . doc\#1... the hope and recovery that is possible for individuals living with a mental health diagnosis....

4. doc\#4... I have described a harsh reality for those of us living with depression....

\subsection{DEPRESSION IS ENEMY:}

The third most prevalent metaphor is an ontological one, where DEPRESSION IS ENEMY in utterances such as:

5 . doc\#2... Instead, we can decide to stop running from it and can choose to beat depression....

6 . Doc\#3...Having a purpose in life can be very effective towards fighting depression.... 


\subsection{DEPRESSION IS AN ABYSS:}

7. doc\#2...spiritual "revivals" made me doubt even more when I would sink into those agnostic depressions....

8. doc $\# 4$...been slipping into depression recently and started smoking....

It is worth noting that sporadic instances of the conceptual metaphor of DEPRESSION IS JOURNEY, which coincides with the general metaphor of STATES ARE JOURNEYS are identified with minimal frequency. There are even fewer instances of mapping subcategories of the JOURNEY metaphor including MEDICATION IS VEHICLE and RECOVERY IS DESTINATION. Examples include expressions such as "It also put me on the road to recovery", "I would come off my medication." However, the frequency of these frames collectively does not exceed 7 hits throughout the corpus. Thus, they are not included within the statistical count.

\begin{tabular}{|l|l|}
\hline Depression metaphor & Frequency of occurrence \\
\hline DEPRESSION IS ENEMY & 95 \\
\hline DEPRESSION IS DISEASE & 90 \\
\hline DEPRESSION IS ABYSS & 65 \\
\hline $\begin{array}{l}\text { DEPRESSION IS } \\
\text { COMPANION }\end{array}$ & 43 \\
\hline
\end{tabular}

Table 1 Frequency of occurrence of DEPRESSION metaphor in MD corpus

\section{BPD Corpus}

The total hits of depression are 2,083 instances in the 919,450word BPD corpus. In this corpus, along the four previously identified metaphorical patterns, it has been observed that the neutral expressions are widely used, such as suffer from depression, experience depression, trigger depression, have depression, etc. The data reveal the DEPRESSION IS COMPANION metaphor as featuring the most frequent, followed by the ABYSS metaphor, then the ENEMY and finally the DISEASE metaphor.

\subsection{DEPRESSION IS COMPANION}

The concordances and frequency of this conceptual metaphor are the most striking both individually or in comparison to the parallel metaphor in the MD corpus. This frame of depression hits 300 times in the corpus. This, as discussed in the section below, indicates a case of submission and acceptance of the disorder, which could either positively 
A Corpus-based Investigation of Conceptual and Pictorial Metaphor of Depression in MD and BPD Patients' Discourse

or negatively affect the treatment procedure. Examples of this pattern include:

9. doc\#0 ...The Power of Peers DBSA envisions wellness for people who live with depression and bipolar disorder.

10.doc\#4... Now I am living with bipolar disorder and managing it in the way that is best for me....

\subsection{DEPRESSION IS AN ABYSS}

Looking into this conceptual metaphor, it is found that there are 52 hits "into depression", 43 "in depression", 31 "deep depression", with a total of 126 hits. Examples include:

11.doc\#1...I don't talk to him. But when I slip into depression again, he comes back....

12.doc\#3... and I was very close to the bottom with my own moods and addictions"

\subsection{DEPRESSION IS ENEMY:}

The ENEMY/OPPONENT depression metaphor comes third in the rate of frequency with 97 hits that feature in expressions such as fight depression, beat bipolar or struggle with mental disorder. Examples include:

13.doc $\# 0$... most people have no idea that I struggle with hypomania and depression....

14. doc\#3 .... So you bother, because bothering means beating bipolar back....

\subsection{DEPRESSION IS DISEASE}

In contrast with the MD corpus, conceptualizing depression as a disease features much less in the BPD corpus with only 53 hits, covering all expressions such as "depression treatment", "chronic depression', or "diagnose depression". For example:

15.doc\#3 ...good therapist can have powerful effects beyond a mood stabilizer in treating bipolar depression and helping prevent relapses....

16.doc\#2...Starting off with being diagnosed with chronic depression.... 
Nihal Nagi Abdel Latif Abu el Naga

\begin{tabular}{|l|l|}
\hline Depression metaphor & Frequency of occurrence \\
\hline DEPRESSION IS COMPANION & 300 \\
\hline DEPRESSION IS ABYSS & 126 \\
\hline DEPRESSION IS ENEMY & 97 \\
\hline DEPRESSION IS DISEASE & 53 \\
\hline
\end{tabular}

Table 2 Frequency of DEPRESSION metaphors in BPD corpus

\section{Analysis of visual corpus:}

This section of the analysis focuses on identifying the major metaphorical visual expressions of DEPRESSION in the selected corpus. As noted in the Methodology section, this is carried out in the light of Forceville (2002) pictorial metaphor theory.

To achieve this, each one of the 137 drawings is examined to identify whether or not it realizes pictorial metaphor. This results in identifying 55 drawings that could be tagged as instances of pictorial metaphorical examples. This identification follows the same procedure of pictorial identification adopted by Forceville, where an image, picture, drawing, etc. can instantiate pictorial metaphor, if the two major elements of pictorial metaphor- metaphorical source and metaphorical target- can be identified.

The second step is to identify the major conceptual metaphors that are realized visually through the drawings. This analysis shows that there are three major metaphors that feature in the data; namely; DEPRESSION IS ENEMY, DEPRESSION IS DEATH, and DEPRESSION IS AN ABYSS. This comes as consistent with the verbal data analyzed above. Two other patterns are detected: DEPRESSION IS PRISON, and DEPRESSED PERSON IS BRITTLE OBJECT. However, they only feature 5 times in all. Accordingly, they are not considered as major patterns.

The third step is to categorize these metaphors in terms of Forceville's four types aforementioned.

The analysis shows that the prevalent type of pictorial metaphor that dominates the data is pictorial simile, featuring in 50 drawings. As previously mentioned, this type of metaphor involves the representation of the metaphorical target in the form of the metaphorical source. In other words, the drawing depicts the source itself. So, as elaborated below, DEPRESSION is 'like' DEATH, ENEMY, or ABYSS. The remaining drawings of the selected 55 instantiate 3 instances of hybrid type of pictorial metaphor and 2 instances of contextual type of pictorial metaphor. 
A Corpus-based Investigation of Conceptual and Pictorial Metaphor of Depression in MD and BPD Patients' Discourse

The following drawings are samples of the aforementioned conceptual metaphors:

\section{DEPRESSION IS DEATH:}

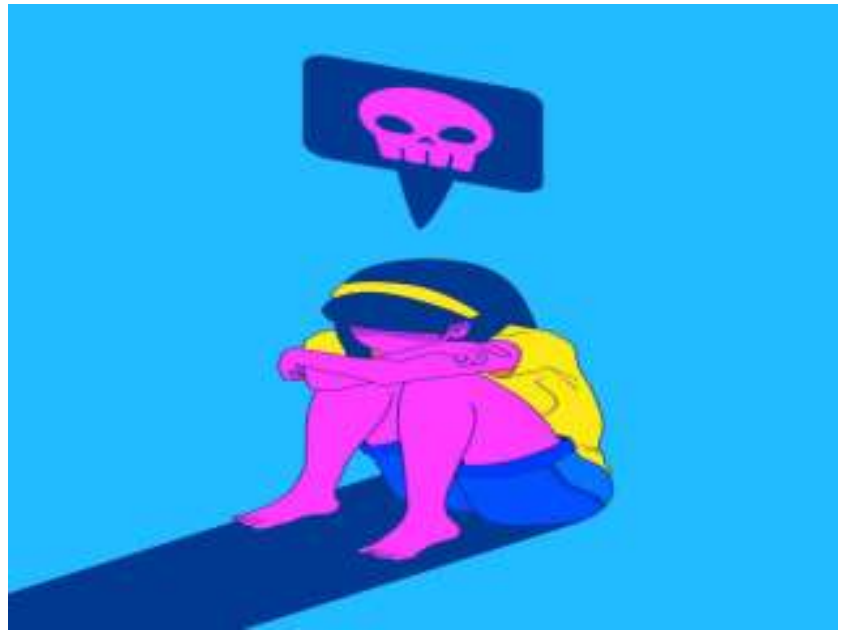

Figure 1

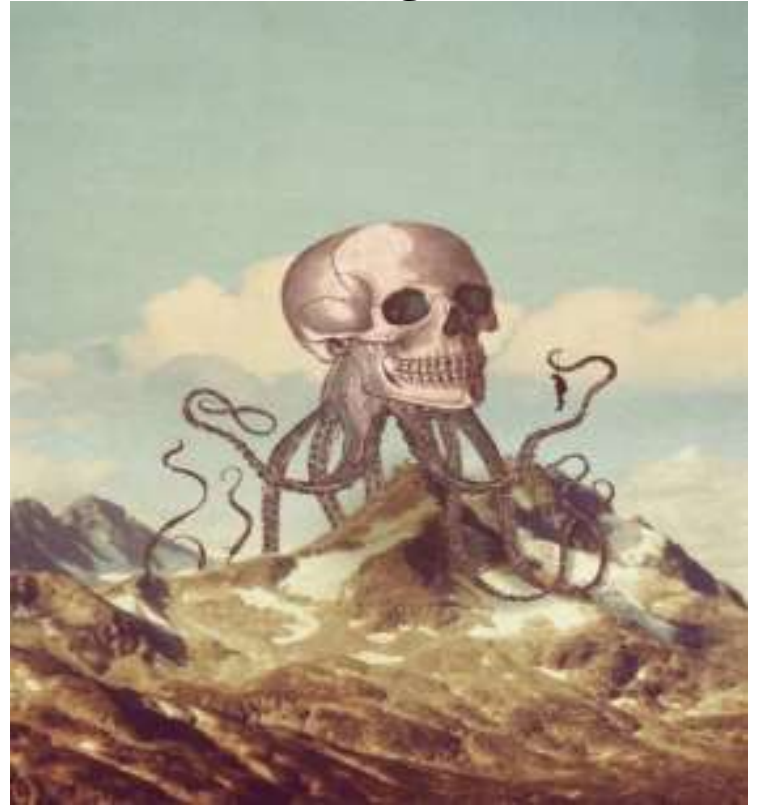

Figure 2

In the above two pictorial simile metaphor drawings, depression is conceptualized as death. As elaborated by Forceville, the metaphorical source (death) is depicted instead of the metaphorical domain (depression). 


\section{Nihal Nagi Abdel Latif Abu el Naga}

DEPRESSION IS ABYSS:

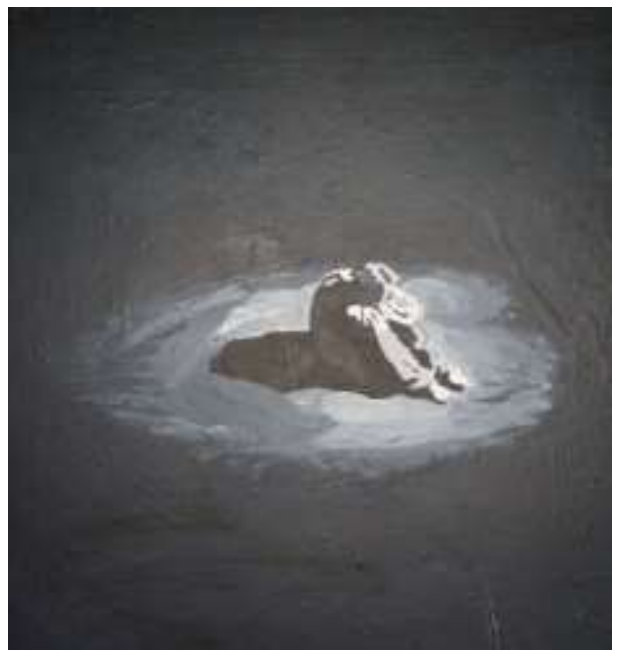

Figure 3

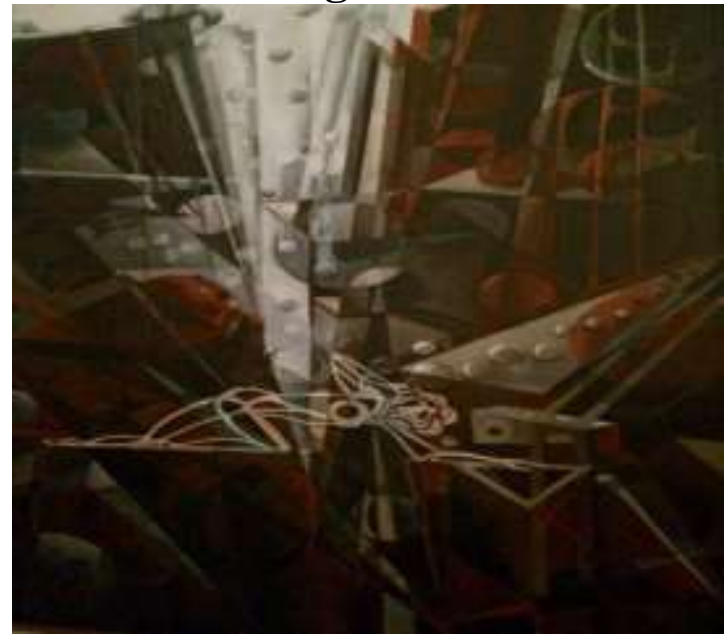

Figure 4

The above two figures are sample pictorial simile metaphor, where the depressed person falls into/ plunges into depression, which is represented visually as a dark, hollow, deep place.

\section{DEPRESSION IS ENEMY:}

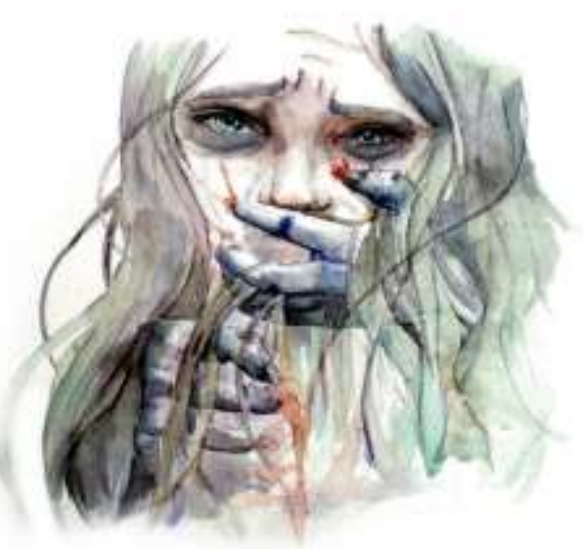


A Corpus-based Investigation of Conceptual and Pictorial Metaphor of Depression in MD and BPD Patients' Discourse

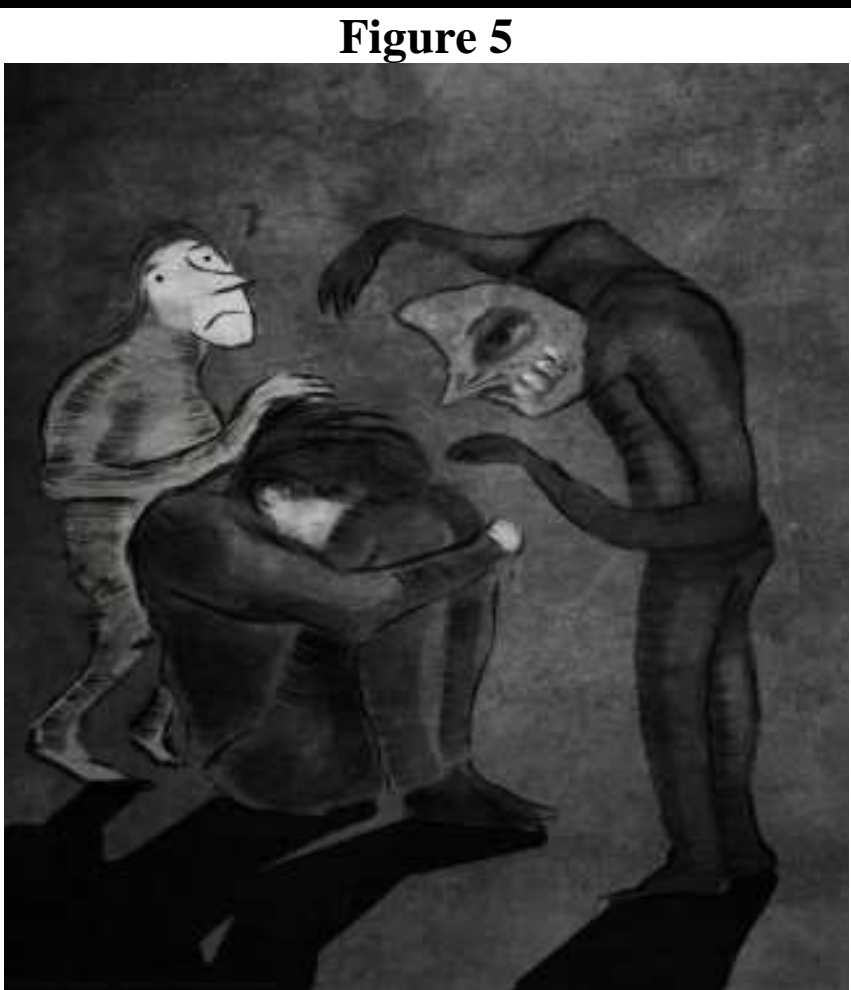

Figure 6

A third sample of pictorial simile metaphor, where DEPRESSION IS ENEMY/ATTACKER, whose hands surround the patient.

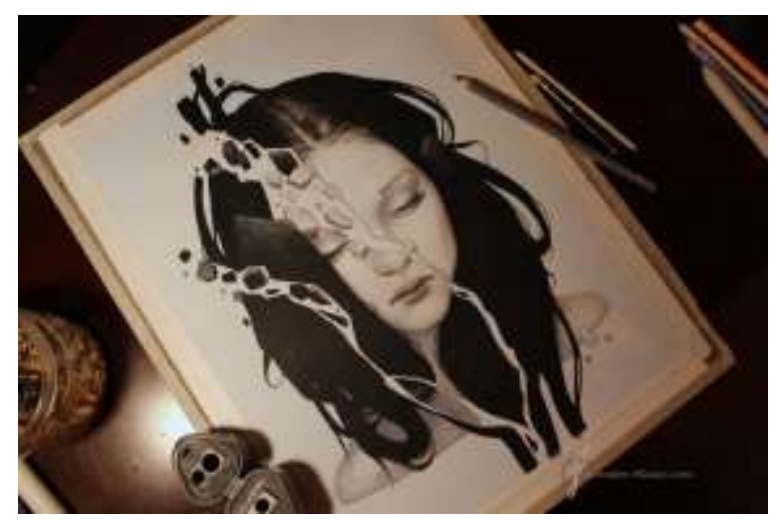

Figure 7 Sample of DEPRESSED PERSON IS BRITTLE OBJECT pictorial simile. 


\section{Nihal Nagi Abdel Latif Abu el Naga}

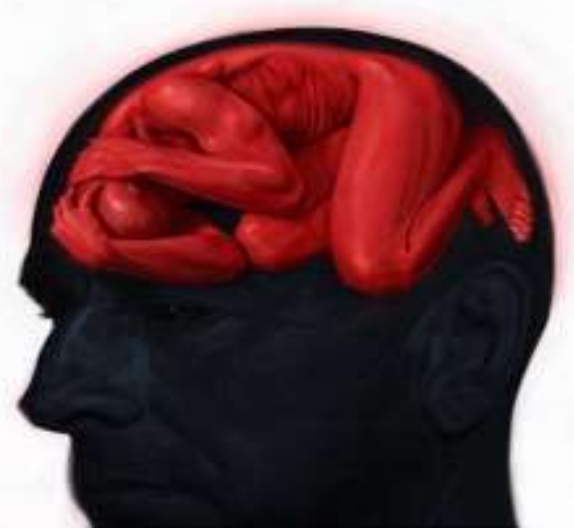

Figure 8 Sample of contextual type of pictorial metaphor, where the metaphorical target (depression) occupies the space occupied by the metaphorical source (brain pain)

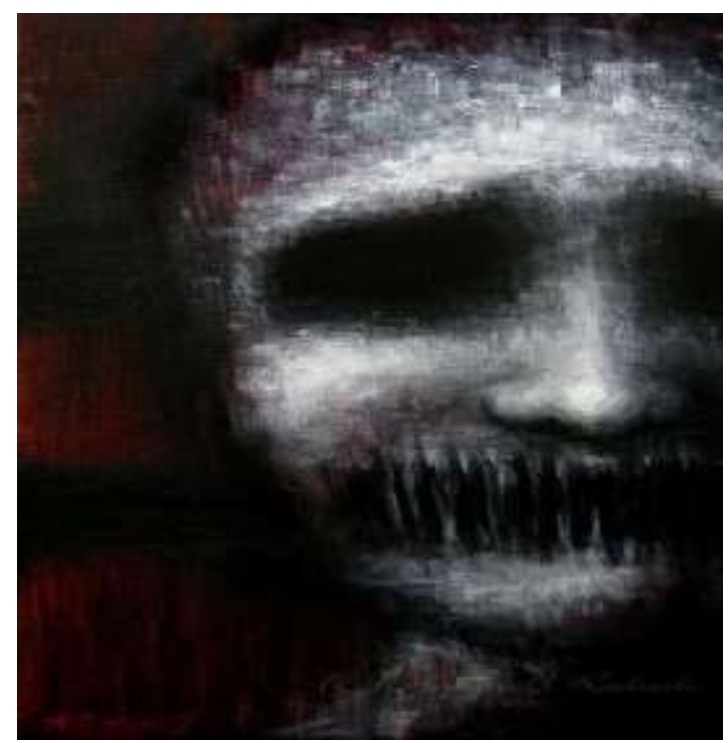

Figure 9 Sample of hybrid type of pictorial metaphor that results from the representation of the metaphorical source and the metaphorical target (ENEMY and DEPRESSION) in one unified concept.

Analyzing the 55 drawings in the same pattern, the following results are obtained:

\begin{tabular}{|l|l|}
\hline Pictorial metaphor & Frequency \\
\hline DEPRESSION IS ENEMY & 20 \\
\hline DEPRESSION IS DEATH & 15 \\
\hline DEPRESSION IS AN ABYSS & 8 \\
\hline DEPRESSION IS PRISON & 2 \\
\hline $\begin{array}{l}\text { DEPRESSED PERSON IS } \\
\text { BRITTLE OBJECT }\end{array}$ & 3 \\
\hline
\end{tabular}

Table 3 Frequency of the major patterns of pictorial metaphors 
Looking at the data in the light of Forceville categorization, the following results are obtained:

\begin{tabular}{|l|l|l|}
\hline Pictorial simile & $\begin{array}{l}\text { Hybrid type of } \\
\text { pictorial metaphor }\end{array}$ & $\begin{array}{l}\text { Contextual type of } \\
\text { pictorial metaphor }\end{array}$ \\
\hline 50 drawings & 3 drawings & 2 drawings \\
\hline
\end{tabular}

Table 4 Frequency of the three major types of pictorial metaphors.

\section{Results and Discussion}

The verbal corpus analysed reveals four major patterns of conceptual metaphors that refer to depression in the analysed discourse. These are DEPRESSION IS A DISEASE, DEPRESSION IS A COMPANION, DEPRESSION IS AN ENEMY and DEPRESSION IS AN ABYSS. The findings related to the ABYSS metaphor are consistent with Lakoff's (1999) general metaphor: EMOTIONS ARE BOUNDED SPACES. They are also consistent with the ANGER IS OPPONENT metaphor, where anger is seen as an opponent in a struggle (p.391) which could be similarly applied to depression.

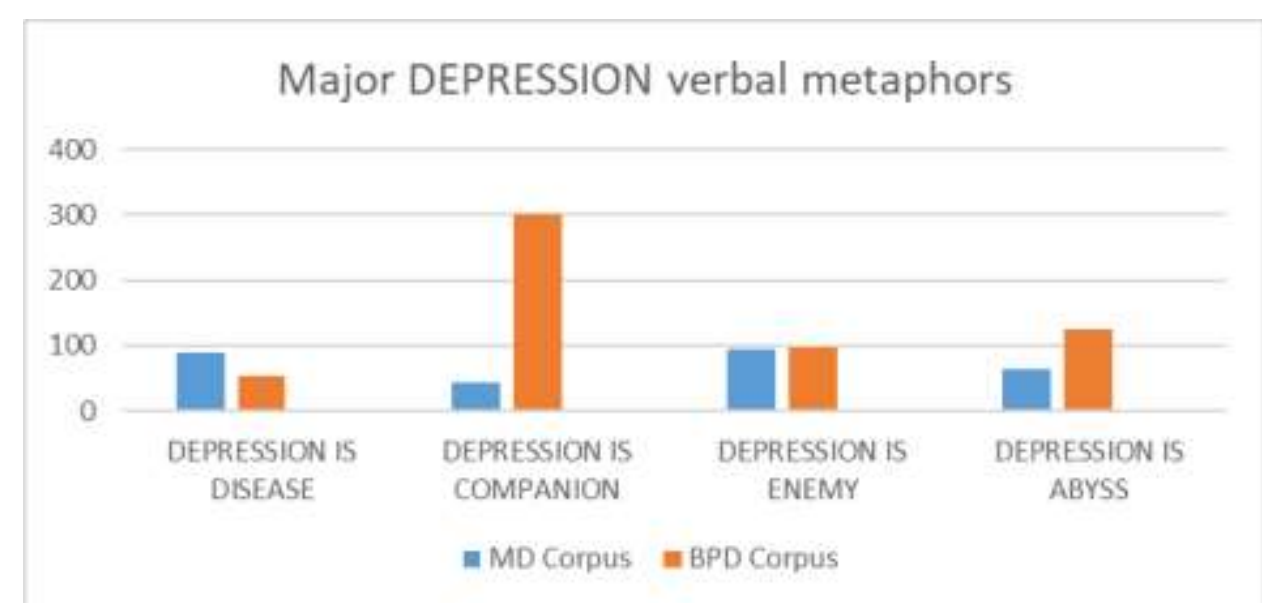

Figure 10 Frequency of occurrence of four DEPRESSION metaphors in MD and BPD corpora

Looking at each corpus, the following findings are noted:

1. The ENEMY metaphor features the most in the MD corpus (95 hits), whereas the COMPANION metaphor hits higher in the BPD corpus (300 hits).

2. The rate of frequency of the ENEMY metaphor is consistent in both corpora (around 95 hits), whereas there is a big discrepancy in the rate of frequency of the COMPANION metaphor, with the BPD corpus features almost ten times that of the MD corpus (35 hits). A similar discrepancy is found between the two corpora in 


\section{Nihal Nagi Abdel Latif Abu el Naga}

the ABYSS metaphor which features in the BPD corpus almost two times (126 hits) that of the MD corpus (63).

Taken together, and according to Conceptual Metaphor Theory, the meaning we give to abstract concepts (depression in the present case) depends partly on how this concept is structured in terms of more concrete entities. Accordingly, metaphors produce systematicity in how concepts are perceived: some features of the mapped source domain come to the foreground and others are backgrounded.

On the other hand, the visual corpus reveals three major depression patterns exemplified as follows:

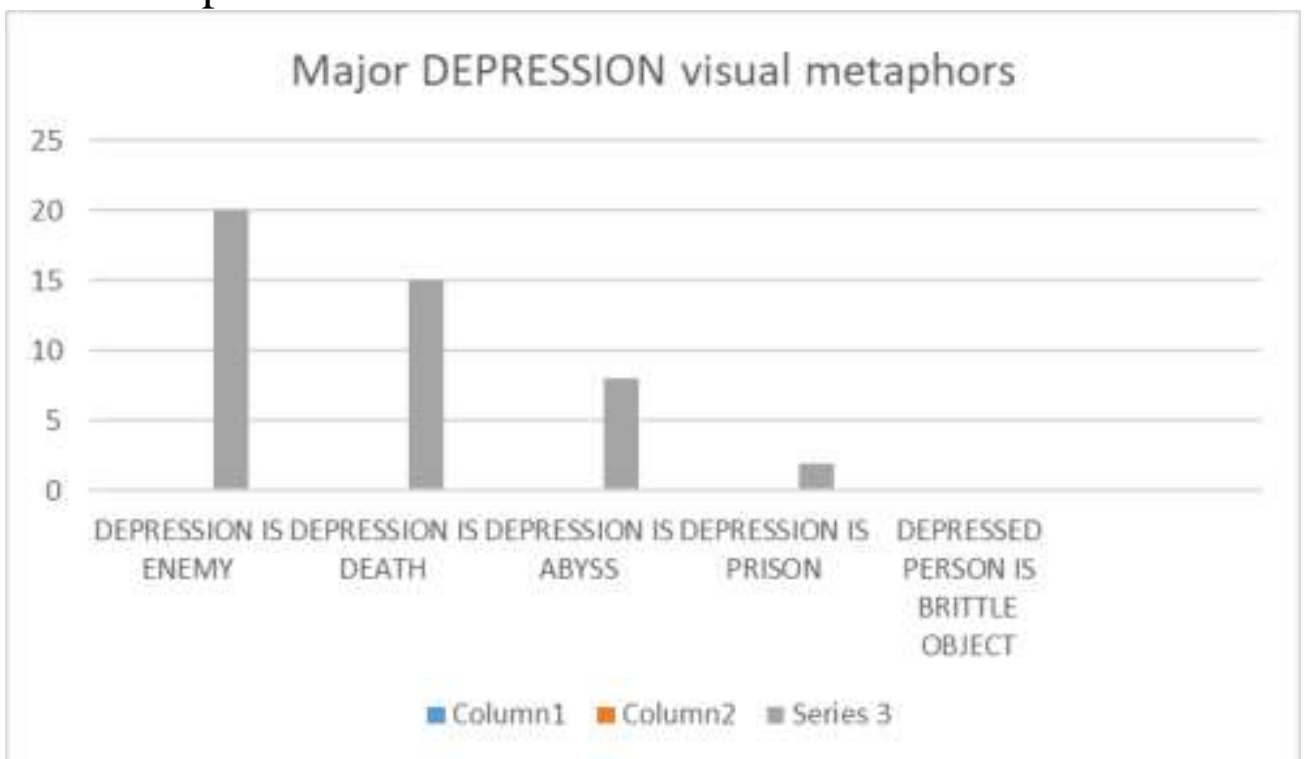

Figure 11 Frequency of occurrence of three DEPRESSION metaphors in Borepanda corpus

Contrasting the findings of the verbal and visual corpora, it can be concluded that:

1. Both corpora include two metaphor patterns: DEPRESSION IS ENEMY and DEPRESSION IS AN ABYSS.

2. Whereas the verbal corpus instantiates the conceptual metaphor DEPRESSION IS DISEASE, the visual corpus has a parallel (and more serious) metaphor, namely: DEPRESSION IS DEATH.

3. There is absolute absence of the DEPRESSION IS COMPANION in the visual data.

4. The visual data does not differentiate between MD or BPD conceptually.

In the light of these findings, and based on the analysis of the verbal corpus, it can be concluded that whereas MD patients think of their disorder more of a physical disease or illness, that is eventually curable or 
at least can be survived through medication, BPD patients think of their disorder rather as a life-time case, that they have to live with in the best case or worse live in, considering that the ABYSS metaphor comes second in the rate of frequency to that of the COMPANION metaphor in the BPD corpus. This, in a way, suggests the weak likelihood of eventual, or at least short-term, recovery. This interpretation is supported through the visual data, where a considerable number of drawings map depression to death, which is another way of representing that it is inevitable.

Along these lines, the results of this study could be guidelines for approaching MD and BPD patients. Disease-like descriptions of psychological problems reduce the sense of responsibility of the 'patient', which suggests that recovery is a matter of proper diagnosis and medication. The rationale behind this is that someone suffering a physical disease is not to blame for that. This is consistent with the established association between reduction of blame and biogenetic explanations of psychological problems (Reali et al., 2015, p.135). On the other hand, framing depression as a COMPANION entails a state of acceptance of one's case, that can either positively or negatively affect how their depression is managed. This is in contrast to the ENEMY metaphor which highlights the role of the patient and the importance of struggling against symptoms or having a fighting attitude. If the patient conceptualizes the mental health condition as an enemy, recovery is a battle that has to be fought and won mainly by the patients themselves, i.e. it is mainly a self-controlled path. Finally, the ABYSS metaphor could be interpreted as one which calls for the help of others, whether doctors or social surrounding to get them out of depression.

\section{Conclusion}

Current trends in mental health discourse suggest that the way people express their psychological disorder reflects and affects how they perceive the problem and its causes, hence lead the way to deal with it. In this paper, investigating the major conceptual metaphors of depression in patients' verbal and visual discourse is seen as a window through which psychiatrists/psychologists can peep into their 'disordered' minds. Through one-to-one sessions, how the patient conceptualizes their case could enlighten the treatment protocol. Looking at the findings of the data analysed could be a first step into proper diagnosis and treatment.

It is further suggested that mental health discourse studies could be incorporated in the newly introduced trend in medical schools, known as medical humanities. This could be of much benefit, especially when dealing with psychological disorders. 


\section{Nihal Nagi Abdel Latif Abu el Naga}

On another level, similar studies could be done to form a literature of metaphors pertaining to different types of physical or psychological disabilities to constitute the foundation for medical discourse metaphor. The discovery of regularities or consistent patterns could be of much practical value. 
Primary Sources:

\section{References}

Depression Corpus

https://drive.google.com/file/d/1ssDHLHQ1hIEFA5eTLQK2O1HsD7r5r0w2/v iew? usp=drivesdk

Secondary Sources:

Alousque, I.N. (2015). The role of text in the identification of visual metaphors in advertising.

Procedia: Social and behavioural sciences, 212, 309-315.

Charteris-Black, J. (2012). Shattering the Bell Jar: Metaphor, Gender, and Depression.

Metaphor and Symbol, 27, (3), 199-216.

(a) De la Rosa, V.M. (2009). The role of pictorial metaphor in magazine advertising. Revista

(b) Alicantina de Estudios Inglese, 22, 67-180.

(c) Demjén, Z. (2011). Drowning in negativism, self-hate, doubt, madness: Linguistic insights

(d) into Sylvia Plath's experience of depression. Communication \& Medicine, 11, 41-54. https://doi.org/10.1558/CAM.V11I1.18478

(e) Diem-Wille, G. (2008). A therapeutic perspective: the use of drawings in child psychoanalysis

(f) and social science. In K. Leeuwen and C. Jewitt (Eds.), Handbook of visual analysis (pp. 132-147). Sage Publication

(g) El Refaei, E. (2003). Understanding visual metaphor: the example of newspaper cartoons. Visual communication, 2, (1). Sage Publications.

(h) El Refaie, E. and Hörschelmann, K. (2010). Young people's readings of a political cartoon

(i) and the concept of multimodal literacy. Discourse Studies in the Cultural Politics of Education, 31, (2), 195-207. DOI: 10.1080/01596301003679719

(j) El Refaie, E. (2014). Looking on the dark and bright side: Creative metaphors of depression

(k) in two graphic memoirs. Autobiography Studies, 29, (1) , 149174.

Evans, V. and Green, M. (2006). Cognitive linguistics: an introduction. Edinburgh UP.

Eynon, T. (2002). Cognitive linguistics. Advances in psychiatric treatment, 8, 399-407.

Feng, D. and O'Halloran, K. (2013). The visual representation of metaphor: A social semiotic approach. Review of cognitive linguistics, 11, (2), 320-335. 


\section{Nihal Nagi Abdel Latif Abu el Naga}

Forceville, C. (1994). Pictorial Metaphor in Advertisements. Metaphor and Symbolic Activity 9, (1), 1-29. https://doi.org/10.1207/s15327868ms0901

Forceville, C. (2002). The identification of target and source in pictorial metaphors. Journal of Pragmatics, 34, 1-14.

Forceville, C. (2008) 'Metaphors in pictures and multimodal representations,' In R.W. Gibbs (Ed.), The Cambridge Handbook of Metaphor and Thought, 462-482. Cambridge: Cambridge University Press.

Forceville, C and Paling, S. (2018). The metaphorical representation of DEPRESSION in short, wordless animation films. Journal of visual communication.

Retrieved

fromhttps://www.researchgate.net/publication/327799344_The metaphorical_r epresentation_of_DEPRESSION_in_short_wordless_animation_films_eprint ahead of press_Open Access in Jnl of Visual Communication_Septe mber_2018

Frank, A. (1995). The wounded storyteller. University of Chicago Press.

Ginsberg, F. (2012). Disability in the digital age. In A. Heather and D. Miller, D. (Eds.),

Digital anthropology,101-126.

Grady, J. (1997). Foundations of meaning: primary metaphors and primary scenes. Unpublished

Berkeley.

Ph.D. diss. Department of Linguistics, University of California at Grady, J. (2007). Metaphor. In D. Geeraerts and H. Cuyckens (Eds.), Oxford handbook of

cognitive linguistics. Oxford University Press.

Hunt, D. (2015). The many faces of diabetes: A critical multimodal analysis of diabetes pages

on Facebook. Language \& Communication, 43. DOI: 10.1016/j.langcom.2015.05.003

Jewitt, C. (2013). Learning and communication in digital multimodal landscapes. London:

Institute of Education Press.

Kress, G. and van Leeuwen, T. (2006). Reading images: the grammar of visual design.

London: Routledge.

Kövecses, Z. (2000a). The scope of metaphor. In A. Barcelona (Ed.) Metaphor and Metonymy

at the Crossroads, 79-92. Berlin: Mouton.

Kövecses, Z. (2000b). Metaphor and Emotion. Cambridge: Cambridge University Press.

Kövecses, Z. (2005). Metaphor in Culture. Universality and Variation. Cambridge:

Cambridge University Press.

Kövecses, Z. (2010a). Metaphor. A Practical Introduction. Oxford: Oxford University Press. 
A Corpus-based Investigation of Conceptual and Pictorial Metaphor of Depression in MD and BPD Patients' Discourse

Kövecses, Z. (2010b). A new look at metaphorical creativity in cognitive linguistics.

Cognitive Linguistics, 21, (4), 663-697.

Kövecses, Z. (2015) Where Metaphors Come From. Reconsidering Context in Metaphor,

Oxford: Oxford University Press.

Kövecses, Z. (2017). Routledge handbook of language and metaphor. London: Routledge.

Lakoff, G. and Johnson, M. (1980). Metaphors we live by. Chicago: Chicago University Press.

Lakoff, G. and Johnson, M. (1999). Philosophy in the flesh. New York: Basic Books.

Lakoff, G. (2008). The neural theory of metaphor. In R.W. Gibbs, (ed.) The Cambridge Handbook of Metaphor and Thought, pp.17-38. Cambridge: Cambridge University Press.

Lakoff, G. (2012). The Contemporary Theory of Metaphor. In A. Ortony (Ed.), Metaphor

and thought, $2^{\text {nd }}$ edition. https://doi.org/10.1017/CBO9781139173865

Langacker,R. (1987). Foundations of cognitive grammar. Stanford: Stanford University

Press.

Lott, P.R. et al. (2002). Linguistics analysis of the speech output of schizophrenic, bipolar,

and depressive patients. Psychotherapy, 35, 220-227.

Matsuki, K. (1995). Metaphors of anger in Japanese. In J. Taylor \& R.E. Maclaury (Eds.),

Language and the Cognitive Construal of the World, 137-151. http://dx.doi.org/10.1515/9783110809305.137

McMullen, L. M., and Conway, J. B. (2002). Conventional metaphors for depression. In $\mathrm{S}$.

Fussell (Ed.), The verbal communication of emotions,167-181.

O'Halloran, K. et al. (2017). A multimodal mixed methods approach for examining recontextualisation patterns of violent extremist images in online media. Discourse, context and media, 21,18-35. doi: 10.1016/j.dcm.2017.11.004

Parprotte, W. and Driven, R. (Eds.) (1985). The ubiquity of metaphor, 142-155. https://doi.org/10.1080/10118063.1987.9724276

Pragglejaz Group (2007). MIP: A method for identifying metaphorically used words in discourse. Metaphor and Symbol, 22, (1), 1-39.

Reali, F. et al. (2015). How we think about depression: The role of linguistic framing. Revista Latinoamericana de Psicología, 48,(2), 127-136.

Sontag, S (1989). Illness as metaphor and AIDS and its metaphors. London: Penguin Books. 


\section{Nihal Nagi Abdel Latif Abu el Naga}

Semino, E. (2008). Metaphor in Discourse. Cambridge: Cambridge University Press.

Shahrazad, P., M. et al. (2012). A comparative study on basic emotion conceptual metaphors

in English and Persian literary texts. International education studies, 5, 200207.

http://dx.doi.org/10.5539/ies.v5n1p200

Yu, N. (2002). Body and emotion: body parts in Chinese expression of emotion. Pragmatics and cognition, 10, (1), 341-367.

YU, N. (1995). Metaphorical expressions of anger and happiness in Chinese and English. Metaphor and Symbol, 10, 59-92. http://dx.doi.org/10.1207/s1532786 